\title{
Kenaf three-dimensional fabric application in environmental protection
}

\author{
Ge-Xiao ${ }^{1, a} \quad$ Guang-yin Xie ${ }^{2, b} \quad$ Xing-yue Yan ${ }^{3, c}$ \\ School of Textile and Materials, Xi'an Polytechnic University, Xi'an/China ${ }^{1,2,3}$ \\ 852285337@qq.coma1329547482@qq.comb 894502377@qq.comc
}

Keywords: kenaf, three-dimensional fabric, soil and water conservation, the degradation, the environmental protection

\begin{abstract}
This article selects the kenaf as a raw material, through the small sample loom weaving kenaf three-dimensional fabric, and do the performance test for soil and water conservation effect and degradation. Soil and water conservation performance test uses artificial simulated rainfall experiments, which measure time of slope runoff and sediment yield. Degradation of the performance is tested by soil burial method, that every other month take out fabric and measure its quality changes. To think that: kenaf three-dimensional fabric for soil and water conservation and degradation of soil pollution achieve the effect of protecting the environment.
\end{abstract}

\section{Introduction}

With the development of our social economy, which people's living standards continued to improve. People had higher requirement for housing. Building tall buildings everywhere in cities, that the hard cover increased gradually, urban and soil and abandon slag buried streets. People could see green area less and less, eventually led to the city and the surrounding soil and water loss was more and more serious. Therefore, the soil and water conservation, becoming the current environmental governance and it is an important work. Three-dimensional woven fabric was paid more and more attention in industry, which the development and using of $3 \mathrm{~d}$ fabric at home and abroad had reached a high level, and a variety of $3 \mathrm{~d}$ fabric had been applied to various fields, soil and water conservation and cultivation performance just begun, but already had a broad prospect. At present, the environmental pollution was increasingly serious, threatening the quality of our daily life. So, the environment become urgent to need to solve the problem.

\section{The selection of fiber materials}

Because this topic was performance study of soil and water conservation and the cultivation of $3 \mathrm{~d}$ kenaf fabric, so that would consider fiber degradation and whether had to promote vegetation growth. Because natural fibers could improve the soil temperature and humidity conditions, so as to effectively promote the growth and development of plants and kenaf geotextile coverage reduced the soil clay erosion, with increasing soil particles structure. Relying on kenaf woven mesh structure, there was room enough for plants to grow and into the light, and with its own weight attached to the soil surface, and every root of mesh yarn were connected into a small cell of the reservoir, to absorb and rainwater, during drought would slow down the evaporation ${ }^{[1]}$. So the kenaf geotextile was a kind of good soil and water conservation material and had good ecological benefits.

\section{Fabric development}

During the design of experiment, according to the woven fabric structure parameters of the 
influence of fabric properties, through the understanding of the features of $3 \mathrm{~d}$ woven fabric related and principle of weaving. Fabric raw material chose kenaf, which trying to design and weaving different cross-section of $3 \mathrm{~d}$ tubular woven geotextiles.

\section{Kenaf three-dimensional fabric performance test of soil and water conservation}

\section{Mechanism of soil and water loss}

Serious soil erosion and soil drought were the reason of aggravated the deterioration of the ecological environment. Under the condition of the deteriorating ecological environment, which inhibited the growth of vegetation, and leaded to soil lost protection, and aggravated soil erosion. Therefore, it would destroy the balance of the ecological environment. Leading to dust storms occured frequently in recent years, the air quality was severely affected ${ }^{[2]}$. China was the most populous country in the world, as the population continued to grow, such problems as lack of resources, energy crisis, food shortage would appear, in order to achieve the needs of the development of human society. the destruction of land resources would be more and more heavy, soil erosion and environmental greening question was particularly acute.

\section{Kenaf three-dimensional fabric of soil and water conservation principle}

Geotextiles cover on the soil, which forming a buffer layer in the surface of soil, would reduce the rain to impact velocity, and reduce rainwater runoff formation, thus reducing runoff erosion, so as to achieve the effect of soil conservation. If the larger the aperture of the surface, the more capable of storing rainwater, so as to achieve the effect of the water conservation. Kenaf geotextile had various advantages of natural fiber, especially water imbibition and degradability were superior to composite geotextile.

\section{Kenaf three-dimensional fabric of soil and water conservation in the experiment}

Kenaf geotextiles experiment in soil and water conservation, which were the artificial rainfall simulation methods, because natural rainfall was not conducive to control that rainfall intensity, rainfall time, and runoff were unable to take. Compared before and after the cover of the change of runoff and sediment yield changes. Then under different rainfall intensity for different specifications kenaf geotextile coverage of runoff and sediment yield after comparison and analysis.

\section{The principle of artificial rainfall simulation}

Simulated rainfall experiment uses a mobile device, undersuface of rainfall assembled small type needles, the height distance of rainfall was $8 \mathrm{~m}$. The experiment before adopted to the ring knife method was distanced the surface of the soil from $40 \mathrm{~cm}$ to determine the moisture content and bulk density ${ }^{[3]}$. During test process, the collection of fixed time interval of runoff, that measured the volume of traffic and measured the wet weight, let stand for 24 hours and used rubber pipette bulb to absorb out the upper of water, that drying method was used to determine ediment concentration.

This experiment facilities were developed by xi'an university of technology which the key laboratory of water resources research institute of design mobile rainfall.It was made of the needle type rainfall, constant pressure water supply, water supply pipe and control valves and other parts. This kind of rainfall intensity was easy to control and stable and good uniformity of rainfall. Rainfall was made from organic glass, that the structure shape as shown in figure 1 . On the base plate was equipped with 270 \# 6.5 medical stainless steel needles, stitch $2.6 \mathrm{~cm}$, and each column lined up in a row, so we could ensure uniform in form within the prescribed scope of rainfall. A needle in the rubber floor holes, then the rubber hole embedded within the bottom hole, its main 
purpose was to replace when needle clogging or broken. The floor had a variety of arrangement, in order to make the rainfall device applied in different section size of the soil bin.

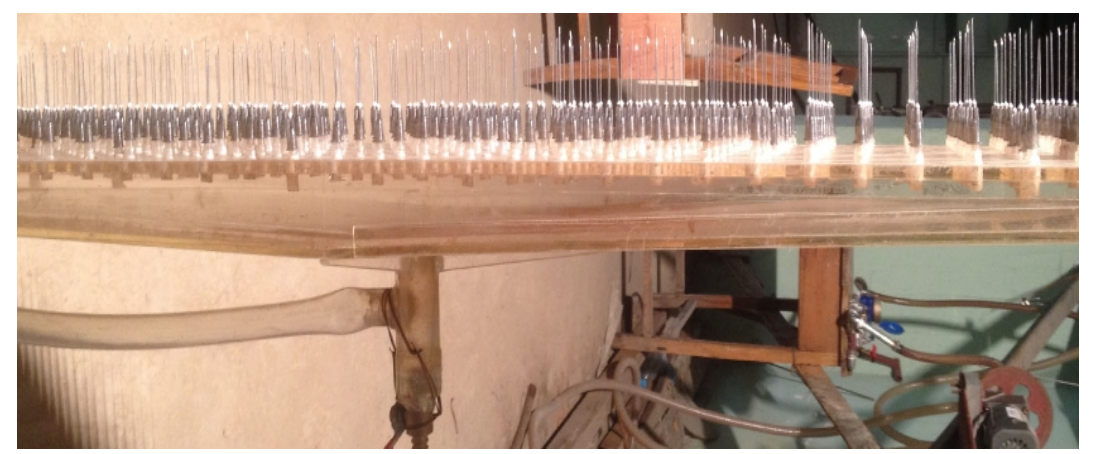

figure 1 Rainfall was flat view

\section{Soil and water conservation effect experiment}

\section{The experimental purpose}

Study of kenaf 3 d geotextiles on soil erosion resistance.

\section{The experimental steps}

(1) Instruments and appliances: electrothermal blowing of 101-3AB, the microwave oven, electronic balance, high altitude movable needle drops of rain, lunch box, measuring cylinder, a stopwatch, suction ears ball.

(2) Sample preparation: take a piece of fabric for $60 \mathrm{~cm}$ length, width was $25 \mathrm{~cm}$ sample piece.

(3) Experimental conditions: slope was $25^{\circ}$, rainfall intensity was $1 \mathrm{~mm} / \mathrm{min}$, rainfall time was $30 \mathrm{~min}$, experimental trough long $640 \mathrm{~mm}$, wide was $290 \mathrm{~mm}$, the thickness was $100 \mathrm{~mm}$, TuRongChong was $1.289 \mathrm{~g} / \mathrm{cm}^{3}$, the water content was $19.9 \%$.

(4) The experimental steps: The experiment soil bin filled with three layers clay and compaction, the top two layers of loaded with initial water content which had a certain soil. The experiment put on kenaf three-dimensional fabric and let it keep fully saturated. Put on the slope of $25^{\circ}$ and cover with plastic after rainfall intensity. Time to water mouth began to water, once every 2 min clock to collect runoff, rainfall total duration for $30 \mathrm{~min}$.

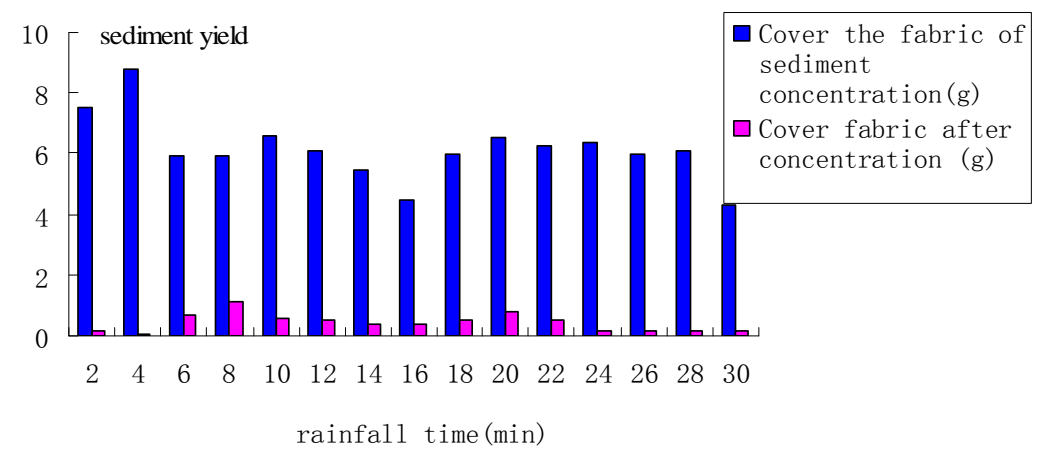

Figure 2 no covering fabric and covering fabric sediment yield contrast 


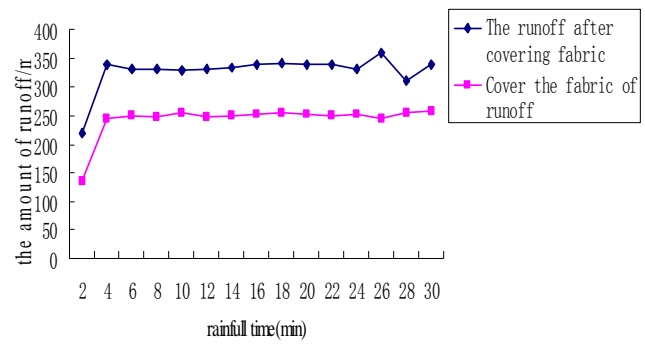

figure 3 Without covering fabric and fabric covering runoff contrast diagram

\section{The experimental data analysis}

Under the condition of artificial rainfall simulation, rainfall intensity was $1 \mathrm{~mm} / \mathrm{min}$, based on the soil bin comparing to the fabric covered and not covered. See below 2 .

Fabric rainfall simulation experiment results were shown in figure 1, 2, 3, figure 1 said that cover fabric before and after the sediment yield comparison chart, the figure could be seen clearly, after covering fabric of rainfall erosion sediment yield decreased significantly. After cover fabric that it would prevented rain directly touch with soil. Therefore, it would avoid raindrops plashing soil. From figure 2, after covering fabric of runoff was superior to cover before the runoff, because rain did not touch with soil directly, part of the water ran away, other part of the water to seep into the fabric directly in order to reach keeping the water.

By figure 3 could be analyzed, after covered fabric and sediment reduction in reducing gradually, with the increase of rainfall time, reduction would tend to be stable and minimum value. Because after the cover fabric from road-related decreased significantly, as to not cover fabric, with the increase of rainfall time decreased and eventually achieved steady trend after increase first, the soil had been destoryed, which the rainwater saturated sediment would achieve stability.

\section{The degradation of kenaf three-dimensional fabric test}

\section{Fabric degradation method}

Biological degradation of the sample test was generally exposed to specific microorganisms, or the embedded in soil and activated sludge were exposed to unqualified fungi and bacteria mixed environment for testing ${ }^{[4]}$. In this experiment mainly would be embedded in the soil sample, let the natural degradation, every other month would be removed from the soil sample for cleaning, drying, weighing, and then analyzed its weight reduction, namely the quality loss method.

\section{Kenaf fabric degradation test}

experimental conditions: outdoor garden temperature and humidity conditions.

\section{the experimental steps:}

(1) with reference to the standard: with reference to Europe and part of the national standard ENV12225-1996-10.

(2) instruments and appliances: a spade, constant temperature oven, electronic balance(2003).

(3) sample preparation: shearing $10 \mathrm{~cm}$ by $10 \mathrm{~cm}$ sample each 5 pieces.( accurate to $1 \mathrm{~mm}$ ).

(4) the experimental principle: soil microbes could be used to make the principle of natural degradation, which about the quality of the samples before and after comparison.

(5) the experimental steps: 9 samples would be prepared to drying, weighing, and then put the 
sample into the pit of $10 \mathrm{~cm}$ off the ground. Every 1 month removed sample for cleaning, drying, weighing, and recorded the data, calculated the loss of quality. Experiment selected in April to September in high temperature and rainy season.

\section{the experimental results and analysis}

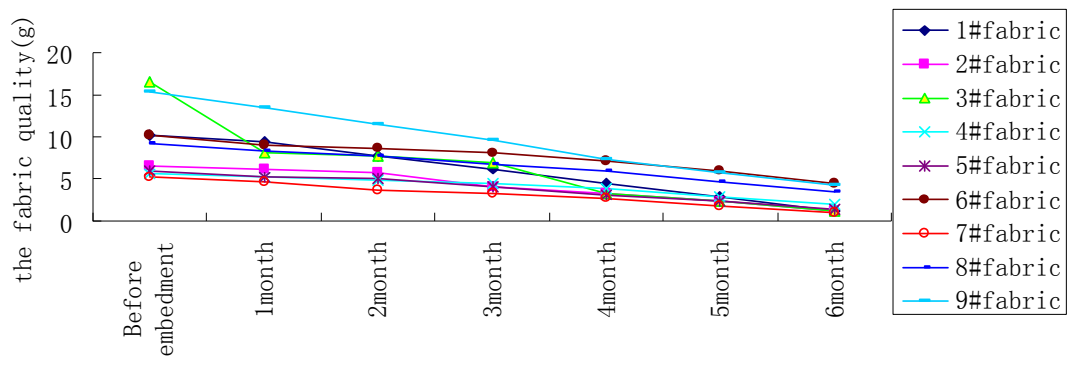

kenaf geotextile degradation(day)

\section{figure 5 kenaf geotextile degrade the quality variation}

Kenaf geotextile degradation of quality change and quality loss rate variation were shown in figure 5, through the analysis after soil buried kenaf geotextile measurement quality degradation, with the increase of sat on a number of days, that gradually reduced the quality of kenaf geotextile. After a year or more than one year, kenaf geotextile could fully biodegradable. Because geotextile was buried in the soil, with the passage of time, the microbes in the fiber surface adhesion in full, then the metabolic activity of microorganisms in the fiber surface gradually strengthened and the fabric would slowly be corrosive and degradable.

\section{Conclusion}

Kenaf geotextile is made up of natural cellulose fiber, after two years it can be natural degradation, thus further growth in plants is not limited. Its breakdown products mainly contains polysaccharide substance and it is beneficial to soil and plants and has the effect of fertilization. There is no need to spend time and money clearing it when vegetation grows up. Kenaf breeding cultivation experiment of $3 \mathrm{~d}$ fabric and degradation experiment prove that kenaf three-dimensional fabric can be fully degradable, and after degradation of soil pollution, which is beneficial to the growth of plants. In addition, it can achieve the effect of soil and water.

\section{References}

[1] Shengli Yan, Zhenwei Gao, Guoli Yang. Urban soil and water conservation and ecological city construction [J]. China's water transport, 2009(4): 162-163.

[2] Guangyin Xie. Woven fabric design principle[M]. Beijing: Chemical industry press, 2004. 10: 121-156.

[3] Xianli Wang, Youshi Zhang,ect. About the key research fields of science and technology of soil and water conservation in our country[J]. China's soil and water conservation science, 2005, 3(1): $1 \sim 6$.

[4] Zaiqin Wang, Zhen Li, Qiang Gao,ect. The influence of jute geotextile degradation of soil fertility[J]. Proceedings of the national academy of sciences, 2000. 10(17): $28 \sim 31$. 